\title{
Pendugaan nilai heritabilitas sifat pertumbuhan pada Sapi Madura
}

\section{Estimates of heritability for growth traits in Madura Cattle}

\author{
Yuli Arif Tribudi ${ }^{*}$, V. M. Ani Nurgiartiningsih ${ }^{2}$ dan Peni W Prihandini ${ }^{3}$ \\ ${ }^{1}$ Program Studi Peternakan, Fakultas Pertanian Universitas Tanjungpura Pontianak \\ ${ }^{2}$ Fakultas Peternakan, Universitas Brawijaya Malang \\ ${ }^{3}$ Loka Penelitian Sapi Potong Grati Pasuruan
}

Submitted: 21 Januari 2019, Accepted: 16 Juli 2019

\begin{abstract}
ABSTRAK: Sumber daya genetik sapi lokal di Indonesia yang perlu dikembangkan salah satunya sapi Madura. Tujuan dari penelitian adalah untuk menduga nilai heritabilitas sifat pertumbuhan pada populasi sapi Madura di Pulau Madura. Materi yang digunakan dalam penelitian menggunakan data recording mulai tahun 2011 sampai 2016 dengan jumlah data berat lahir (190 ternak), berat 205 hari (155 ternak) dan berat 365 hari (135 ternak). Nilai heritabilitas dihitung dengan menggunakan korelasi saudara tiri sebapak (paternal half sib correlation). Hasil penelitian menunjukkan bahwa nilai heritabilitas berat lahir, berat 205 hari dan berat 365 hari pada populasi sapi Madura masing-masing yaitu $0,38 \pm 0,17 ; 0,64 \pm 0,22$ dan $0,54 \pm 0,18$. Nilai heritabilitas sifat pertumbuhan pada populasi sapi Madura termasuk kategori sedang sampai tinggi, sehingga sifat tersebut dapat dijadikan sebagai kriteria seleksi untuk peningkatan produktivitas sapi Madura sebagai sapi lokal Indonesia.
\end{abstract}

Kata kunci: sifat pertumbuhan; sapi Madura; heritabilitas.

ABSTRACT: Madura, a local cattle breed in Indonesia, is included as a national genetic resource. Genetic evaluation for growth traits in Madura cattle is important for appropriate utilization and improvement of this breed. The aim of this study was to estimate the heritability for growth traits in Madura cattle. The method used in this study is a data recording from 2010 until 2016 including birth weight (190 animals), weight at day 205 (155 animals) and weight at day 365 (135 animals) were used for heritability estimates by using paternal half sib correlation. The results showed that heritability estimates for birth weight, weight at day 205 and weight at day 365 were $0.38 \pm 0.17 ; 0.64 \pm 0.22$ dan $0.54 \pm 0.18$. Estimates of heritability for growth traits in Madura cattle ranged between medium and high. In conclusion, growth traits can be used as selection criteria for future genetic improvement in Madura cattle.

Keywords: growth traits; madura cattle; heritability.

*Corresponding Author: yuliariftribudi@gmail.com 


\section{PENDAHULUAN}

Bangsa sapi lokal yang ada di Indonesia diantaranya adalah sapi Madura. Sapi Madura mempunyai peranan sangat penting sebagai aset Sapi Madura, tenaga kerja dan pariwisata (sapi Karapan dan sapi Sonok) di Indonesia. Ada sekitar 4,5 juta sapi Madura di Jawa Timur dan sekitar 950 ribu ekor diternakkan di Pulau Madura hampir seluruhnya adalah sapi Madura (Dinas Peternakan Jawa Timur, 2016). Sapi Madura mempunyai keunggulan dibandingkan dengan sapi eksotik dari kemampuan mencerna pakan dengan kualitas rendah, adaptif pada iklim panas dan ektoparasit khususnya caplak serta mampu berproduktivitas di daerah marginal (Ma'sum, 1992).

Potensi genetik sifat kuantitatif (berat lahir, berat sapih, berat setahun, pertumbuhan sebelum sapih, dan pertumbuhan setelah sapih) dalam suatu populasi digambarkan dengan nilai parameter genetik. Nilai parameter genetik khususnya heritabilitas digunakan dalam pelaksanaan seleksi untuk peningkatan produktivitas sapi Madura. Pengetahuan nilai heritabilitas dalam program pemuliaan khususnya seleksi dapat memprediksi kemajuan genetik berdasarkan respon seleksi. Jumlah populasi, tempat dan metode penaksiran yang digunakan mempengaruhi nilai parameter genetik. Mutu genetik sapi Madura di seluruh pulau Madura secara umum dapat ditingkatkan dengan diketahuinya nilai parameter genetik walaupun populasi sapi Madura di setiap kabupaten yang dijadikan sampel. Hal ini didasarkan kinerja ternak tidak mempengaruhi nilai heritabilitas akan tetapi dipengaruhi keragaman populasi tersebut.

Peningkatan mutu genetik sapi Madura salah satunya adalah melalui seleksi yang diarahkan untuk menghasilkan sapi Madura seperti tetuanya yang diharapkan keunggulannya dapat diwariskan kepada anaknya. Hal ini dapat dilakukan apabila nilai heritabilitas yang menunjukkan persentase keunggulan tetua yang diwariskan kepada anaknya terlebih dahulu diestimasi melalui berat lahir dan berat prasapihnya. Faktor penting yang mempengaruhi produktivitas ternak salah satunya adalah berat lahir (Hardjosubroto, 1994). Berat sapih dipengaruhi oleh berat lahir karena ternak yang berat lahirnya diatas rataan mempunyai kemampuan hidup yang tinggi dan pertumbuhan cepat sehingga memilik berat sapih yang tinggi pula.

Nilai heritabilitas tinggi atau sedang maka perbaikan mutu genetik dengan cara seleksi akan lebih efektif sedangkan untuk nilai heritabilitas rendah maka program persilangan dengan diikuti seleksi akan lebih tepat. Tujuan penelitian ini adalah menduga nilai heritabilitas sifat pertumbuhan sapi Madura sehingga dengan diketahuinya nilai heritabilitas pada sifat tersebut maka didapatkan suatu program pemuliaan yang berkesinambungan guna membantu penentuan strategi perbaikan mutu sapi Madura.

\section{MATERI DAN METODE Materi Penelitian}

Penelitian dilakukan di Kabupaten Bangkalan, Sampang, Pamekasan dan Sumenep. Penentuan sample menggunakan purposive sampling yaitu sapi-sapi yang berada di agroekosistem relatif sama. Materi yang digunakan dalam penelitian menggunakan data recording mulai tahun 2011 sampai 2016 dengan jumlah data yang digunakan disetiap Kabupaten berdasarkan kelompok umur disajikan pada Tabel 1. 
Tabel 1. Jumlah sampel penelitian sapi Madura berdasarkan kelompok umur di setiap Kabupaten (ekor)

\begin{tabular}{lccc}
\hline Kabupaten & Lahir & Umur & \\
& 46 & 38 & 365 hari \\
\hline Bangkalan & 42 & 34 & 35 \\
Sampang & 63 & 47 & 30 \\
Pamekasan & 39 & 36 & 36 \\
Sumenep & 190 & 155 & 34 \\
\hline Total & & & 135 \\
\hline
\end{tabular}

\section{Analisis Data}

Metode yang digunakan dalam penelitian ini adalah studi kasus dengan menggunakan data recording. Data yang diamati meliputi :

1. Berat lahir adalah berat pedet yang dihasilkan dari penimbangan pada waktu pedet dilahirkan atau maksimal 3 (tiga) hari setelah pedet dilahirkan (Direktorat Jenderal Peternakan, 2007).

2. Berat 205 hari merupakan berat sapi Madura disapih dan disesuaikan pada umur 205 hari serta diasumsikan sapi ditimbang pada umur yang seragam yaitu 205 hari. Rumus yang digunakan adalah sebagai berikut (Hardjosubroto, 1994) :

$$
\mathrm{BS}_{205 \text { hari }}=\left(\frac{\mathrm{BB}-\mathrm{BL}}{\text { Umur }} \times 205+\mathrm{BL}\right)
$$

Keterangan :

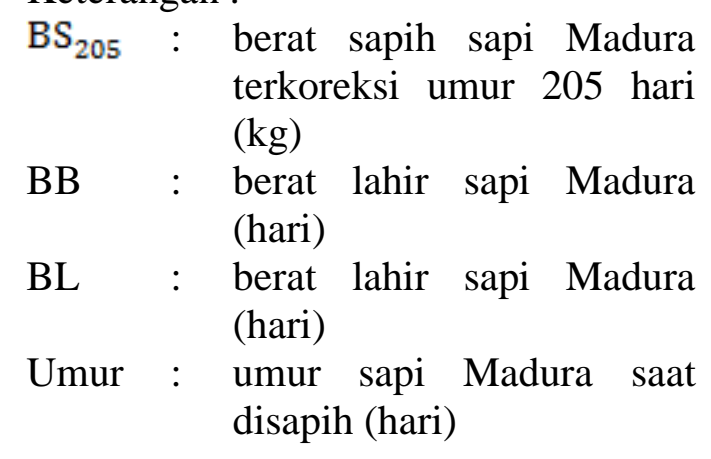

3. Berat 365 hari atau berat setahun, perhitungan data berat satu tahun disesuaikan pada umur 365 hari karena sapi ditimbang dengan variasi umur yang beragam. Perhitungan menggunakan rumus sebagai berikut (Hardjosubroto, 1994) :

$$
\mathrm{BB}_{365 \text { hari }}=\frac{\mathrm{BB}-\mathrm{BS}}{\text { tenggang waktu }} \times 160+\mathrm{BS}_{205}
$$

Keterangan :

$\mathrm{BB}_{365}$ : berat badan sapi Madura terkoreksi umur 365 hari (kg)

BB : berat badan sapi Madura saat ditimbang $(\mathrm{kg})$

BL : berat sapih sesungguhnya (tanpa koreksi) (kg)

Tenggang : jarak waktu antara saat waktu sapih dengan penimbangan ternak (hari)

\section{Pendugaan Heritabilitas}

Pendugaan komponen ragam nilai heritabilitas berat badan lahir, 205 hari dan 365 hari pada sapi Madura melalui analisis Restricted Maximum Likelihood (REML) pola Linear Mixed Model dengan program Genstat $12.2^{\text {th }}$. Kabupaten dan jenis kelamin digunakan sebagai factor pengaruh tetap sementara faktor pejantan sebagai faktor pengaruh acak. Persamaan statistik Linear Mixed Model adalah sebagai berikut:

$$
\mathrm{Y}=\mathrm{X}_{\mathrm{T}} \pm \mathrm{Z}_{\mathrm{u}} \pm \mathrm{e}
$$

Keterangan:

$\mathrm{Y}$ : vektor pengamatan ( $\mathrm{n} \times 1)$

$\mathrm{T}$ : vektor dan pengaruh tetap ( $\mathrm{x}$ 1)

$\mathrm{u} \quad$ : vektor dari pengaruh acak (b x 1)

$\mathrm{X}$ : matriks yang berkaitan dengan pengaruh tetap 
(n $x \mathrm{t})$

$\mathrm{Z}$ : matriks yang berkaitan dengan pengaruh acak

$(\mathrm{n} \times \mathrm{b})$

e : vektor error $(\mathrm{n} \times 1)$

Sumber: Knight (2008)

Heritabilitas diduga dengan metode korelasi saudara tiri sebapak (paternal half sib correlation) dengan persamaan:

$$
\mathrm{h}^{2}=\frac{4 \sigma_{S}^{2}}{\sigma_{S}^{2}+\sigma_{E}^{2}}
$$

Keterangan:

$\begin{array}{ll}\mathrm{h}^{2} & =\text { heritabilitas } \\ \sigma_{\mathrm{g}}^{2} & =\text { ragam pejantan } \\ \sigma_{\mathrm{E}}^{2} & =\text { ragam error }\end{array}$

Perhitungan simpangan baku heritabilitas menggunakan rumus:

$$
\mathrm{SE}\left(\mathrm{h}^{2}\right)=4 \sqrt{\frac{2(\mathrm{n}-1)(1-\mathrm{t})^{2}[1 \pm(\mathrm{k}-1) \mathrm{t}]^{2}}{\mathrm{k}^{2}(\mathrm{n}-1)(\mathrm{s}-1)}}
$$

$$
\begin{gathered}
\mathrm{k}=\frac{1}{\mathrm{~s}-1}\left(\mathrm{n}-\frac{\sum \mathrm{n}^{2}}{\mathrm{n}}\right) \\
\mathrm{t}=\frac{\sigma_{S}^{2}}{\sigma_{S}^{2}+\sigma_{E}^{2}}
\end{gathered}
$$

Keterangan :

$\mathrm{k}=$ koefisien

$\mathrm{t}=$ korelasi dalam kelas

$\mathrm{n} \quad=$ jumlah keturunan

$\mathrm{s} \quad=$ jumlah pejantan

\section{HASIL DAN PEMBAHASAN \\ Berat Badan}

Sifat kuantitatif adalah sifat-sifat yang dapat diukur pada seekor ternak baik untuk sifat produksi seperti berat badan dan ukuran morfologi tubuh. Tabel 2 menunjukan rataan berat badan sapi Madura pada umur lahir, 205 hari dan 365 hari di empat Kabupaten di pulau Madura.

Tabel 2. Rataan dan standar deviasi berat badan sapi Madura berdasarkan kelompok umur di setiap Kabupaten $(\mathrm{kg})$

\begin{tabular}{lccc}
\hline Kabupaten & \multicolumn{3}{c}{ Umur } \\
\cline { 2 - 4 } & Lahir & 205 hari & 365 hari \\
\hline Bangkalan & $18,07 \pm 1,60$ & $93,39 \pm 5,78$ & $120,63 \pm 4,71$ \\
Sampang & $19,17 \pm 1,20$ & $95,06 \pm 6,71$ & $119,53 \pm 9,70$ \\
Pamekasan & $18,78 \pm 1,09$ & $92,73 \pm 3,16$ & $121,00 \pm 5,11$ \\
Sumenep & $18,38 \pm 1,98$ & $92,07 \pm 6,71$ & $122,85 \pm 9,43$ \\
\hline Rataan Total & $18,44 \pm 1,72$ & $93,96 \pm 6,21$ & $121,05 \pm 7,80$ \\
\hline
\end{tabular}

Hasil perhitungan statistik menunjukkan bahwa tidak terdapat perbedaan rataan berat badan lahir, BB 205 hari dan BB 365 hari sapi Madura di empat Kabupaten. Faktor lingkungan yang hampir sama menyebabkan tidak berbedanya berat badan sapi Madura di keempat lokasi penelitian. Kondisi sosial-ekonomi dan wilayah peternak yang hampir sama mempengaruhi manajemen pemeliharaan serta jenis pakan sehingga mempengaruhi ukuran tubuh sapi Madura antar subpopulasi.
Rataan berat lahir sapi Madura pada penelitian ini sebesar 18,44 $\pm 1,72 \mathrm{~kg}$ (Tabel 2) lebih tinggi dari laporan Karnaen (2004) sebesar $14,51 \mathrm{~kg}$ tetapi lebih rendah hasil penelitian Nurgiartiningsih (2011) sebesar $20,74 \pm 3,44 \mathrm{~kg}$. Perbedaan berat lahir sapi Madura dengan penelitian yang lain diduga karena pengetahuan peternak dan kualitas pengelolaan yang semakin bak sehingga terjadi peningkatan performans serta waktu, lokasi dan populasi penelitian yang berbeda. 
Pada Tabel 2 digambarkan rataan berat badan sapi Madura 205 hari dan 365 hari di semua kabupaten masing-masing sebesar $93,96 \pm 6,21 \mathrm{~kg}$ dan $121,05 \pm 7,80 \mathrm{~kg}$. Karnaen dan Arifin (2007) melaporkan berat badan sapi Madura umur 5 bulan sebesar $62,36 \mathrm{~kg}$ dan Nurgiartiningsih (2011) sebesar $73,16 \pm 8,84 \mathrm{~kg}$ sementara itu Sulistiyoningtyas dkk (2017) menyatakan berat badan sapi Madura 365 hari sebesar $120 \pm 10,86 \mathrm{~kg}$.

Kualitas dan kuantitas pakan serta manajemen pemeliharaan yang berbeda akibat peningkatan pengetahuan peternak tentang pemeliharaan sapi Madura diduga me- nyebabkan terjadinya peningkatan berat badan sapi Madura tersebut. Selain itu juga dipengaruhi kemampuan induk (mothering ability). Produksi susu induk mempengaruhi pertumbuhan anak sapi setelah lahir, jika produksi susu yang terbatas akibat manajemen pemelihraan yang buruk akan menyebebkan keterlambatan pertumbuhan anak sapi.

\section{Heritabilitas}

Pendugaan nilai heritabilitas berat badan sapi Madura pada umur lahir, 205 hari dan 365 hari pada sapi Madura disajikan pada Tabel 3.

Tabel 3. Nilai heritabilitas berat lahir, 205 hari dan 365 hari sapi Madura

\begin{tabular}{ll}
\hline Parameter & Heritabilitas \\
\hline Berat lahir & $0,38 \pm 0,17$ \\
Berat 205 hari & $0,64 \pm 0,22$ \\
Berat 365 hari & $0,54 \pm 0,18$ \\
\hline
\end{tabular}

Nilai pendugaan heritabilitas yang dihasilkan termasuk dalam kategori sedang dan tinggi dengan nilai heritabilitas berat lahir $(0,38 \pm 0,17)$; berat badan 205 hari $(0,64 \pm 0,22)$ dan dan berat badan 365 hari $(0,54 \pm 0,18)$. Nilai heritabilitas berat badan pada umur lahir tidak berbeda dengan penelitian Tribudi dan Nurgiartiningsih (2014) sebesar $0,31 \pm 0,19$, sedangkan nilai heritabilitas berat 205 hari lebih rendah daripada laporan Karnaen (2004) serta Tribudi dan Nurgiartiningsih (2014) sebesar $0,87 \pm 0,45$ dan $0,62 \pm 0,20$ sementara itu pada untuk berat 365 hari lebih tinggi dibandingkan penelitian Karnaen (2004)

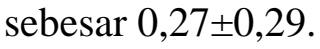

Perbedaan populasi diduga menyebabkan perbedaan nilai heritabilitas berat lahir; berat 205 hari dan berat 365 hari pada sapi Madura. Selain itu, perbedaan metode analisis juga dapat menyebabkan perbedaan nilai heritabilitas yang diperoleh (Kinghorn, 2002). Bagian dari keragaman total yang disebabkan oleh pengaruh genetik disebut juga dengan heritabilitas, apabila terjadi perubahan komponen ragam penyusunnya akan menyebabkan perbe- daan nilai heritabilitas (Lasley, 1978). Nilai heritabilitas dapat meningkat jika ragam lingkungan menurun dan ragam genetik meningkat begitupun sebaliknya dapat menyebabkan nilai heritabilitas menurun. Perbedaan ragam genetik dan lingkungan pada setiap periode waktu, tempat atau populasi sapi Madura saat diukur akan menghasilkan hasil estimasi nilai heritabilitas yang berbeda. Kurnianto (2009) menambahkan nilai heritabilitas suatu sifat tertentu pada suatu populasi merupakan karakter spesifik dari populasi tersebut.

Sifat yang mempunyai heritabilitas tinggi atau sedang, maka seleksi lebih efektif dan efisien untuk perbaikan mutu genetik ternak karena memberikan respon yang besar. Nilai heritabilitas yang tinggi diperoleh pada heritabilitas berat badan 205 hari sehingga dapat digunakan sebagai pedoman seleksi sapi Madura. Apabila didasarkan pada standar error nya maka umur tersebut juga dapat digunakan sebagai pedoman seleksi, karena keakuratan nilai heritabilitas dapat ditentukan dengan semakin kecil nilai standar eror maka heritabilitas akan semakin akurat. Berat badan 
umur 205 hari berkaitan dengan berat sapih karena merupakan salah satu kriteria seleksi yang baik dalam peningkatan mutu genetik sapi potong.

Seleksi pada sapi potong banyak dititik beratkan pada berat badan umur tertentu yang secara ekonomis menguntungkan. Berat badan yang sering digunakan sebagai kriteria seleksi adalah berat sapih dan berat setahun; pertambahan berat badan harian pra-sapih dan pasca sapih (Hardjosubroto, 1994). Seleksi pada dasarnya adalah pemilihan ternak unggul secara genetik untuk dijadikan tetua pada generasi mendatang sehingga diharapkan keturunannya memiliki peroformans genetik yang lebih unggul daripada tetuanya.

\section{KESIMPULAN}

Nilai heritabilitas berat lahir, umur 205 hari dan 365 hari sapi Madura termasuk bernilai sedang sampai tinggi sehingga sehingga dapat digunakan sebagai pedoman seleksi untuk peningkatan produktivitas sapi Madura sebagai sapi lokal Indonesia

\section{DAFTAR PUSTAKA}

Dinas Peternakan Provinsi Jawa Timur., 2016. Buku Statistik Ternak Provinsi Jawa Timur. Dinas Peternakan Jawa Timur, Surabaya.

Direkorat Jenderal Peternakan., 2007. Petunjuk Teknis Uji Performans Sapi Potong Nasional. Kementerian Pertanian. Jakarta.

Hardjosubroto, W., 1994. Aplikasi Pemuliaan Ternak di Lapang. Gramedia. Jakarta

Karnaen dan J. Arifin., 2007. Kajian Produktivitas Sapi Madura. Jurnal Ilmu Ternak, Desember, 7(2), 135 - 139

Karnaen. 2004. Model Kurva Pertumbuhan Sapi Madura Betina dan Jantan Dari Lahir Sampai Umur Enam Bulan. Jurnal Ilmu Ternak, 7(1), 48 - 51.
Kinghorn, B., 2002. Full Program with All Tecnologies and Fasilities Available. Working Papers: Bali Cattle Workshop. Bali, 4-7 February 2002.

Knight, E., 2008. Improved Iterative Scemes for REML estimation of Variance Parameters ini Linear Mixed Models. School of Agriculture, Food and Wine. The University of Adelaide. Adelaide.

Kurnianto, E. 2009. Pemuliaan Ternak. Graha Ilmu. Yogyakarta.

Lasley, J.F., 1978. Genetics of Livestock Improvement. Prentice Hall, Inc. Englewood Cliffs. New Jersey.

Ma'sum, K. 1992. Hasil Penelitian Sapi Madura di Sub Balai Penelitian Ternak Grati. Prosiding Pertemuan Ilmiah Hasil Penelitian dan Pengembangan Sapi Madura. Sub Balai Penelitian Ternak Grati. Pasuruan: 45-54.

Nurgiartiningsih, W. M. A., 2011. Peta Potensi Genetik Sapi Madura Murni di Empat Kabupaten di Madura. J. Ternak Tropika, 12(2), 23-32, 2011

Sulistiyoningtyas, $\quad$ I., $\quad$ V.M.A. Nurgiartiningsih, dan G. Ciptadi. 2017. Evaluasi performa bobot badan dan statistik vital sapi madura berdasarkan tahun kelahiran. Jurnal Ilmiah Peternakan Terpadu, 5(2): 40-43

Tribudi, Y.A dan V.M.A. Nurgiartiningsih. 2014. Estimasi heritabilitas sifat kuantitatif pada sapi Madura di Pulau Madura. Prosiding Seminar Nasional Peternakan: Teknologi Dan Agribisnis Peternakan Untuk Akselerasi Pemenuhan Pangan Hewani (Seri II), Purwokerto, 14 Juni 2014. 